\title{
Integrin and cytoskeletal regulation of growth factor signaling to the MAP
}

\section{kinase pathway}

\author{
Andrew E. Aplin and R. L. Juliano* \\ Department of Pharmacology, School of Medicine, University of North Carolina at Chapel Hill, Chapel Hill, NC 27599, USA \\ *Author for correspondence (e-mail: arjay@med.unc.edu)
}

Accepted 22 December 1998; published on WWW 8 February 1999

\section{SUMMARY}

Integrin-mediated anchorage of NIH3T3 fibroblasts to the extracellular matrix component fibronectin permits efficient growth factor signaling to the p42 and p44 forms of mitogen-activated protein kinase (MAPK). Since integrins bridge the extracellular matrix to focal adhesion sites and to the actin cytoskeleton, we analyzed the role of these integrin-associated structures in efficient growth factor activation of p42 and p44-MAPKs. Use of specific reagents that disrupt actin stress fiber and focal adhesion formation demonstrated that upon readhesion of NIH3T3 cells to fibronectin, cells that were poorly spread and lacked prominent focal adhesions but that formed cortical actin structures, efficiently signaled to p42 and p44MAPKs upon EGF stimulation. In contrast, failure to form the cortical actin structures, despite attachment to fibronectin, precluded effective EGF signaling to p42 and p44-MAPKs. Actin cytoskeletal changes induced by expression of dominant-negative and constitutively active forms of Rho GTPases did not alter EGF activation of MAPK in adherent cells. However, active Cdc42, but not active Rac1 or RhoA, partially rescued EGF signaling to p44-MAPK in cells maintained in suspension. These data indicate that a limited degree of adhesion-mediated cytoskeletal organization and focal adhesion complex formation are required for efficient EGF activation of p42 and p44-MAPKs. Our studies exclude a major role for the GTPases RhoA and Rac1 in the formation of cytoskeletal structures relevant for signaling, but indicate that structures regulated by $\mathrm{Cdc4} 2$ enhance the ability of suspension cells to activate MAPK in response to growth factors.

Key words: Integrin, MAPK, Actin, Cdc42, RhoA

\section{INTRODUCTION}

The proliferation of most normal cells requires a state of adherence, as well as the presence of circulating mitogenic growth factors. For example, 3T3 fibroblasts maintained in suspension will arrest in the $\mathrm{G}_{1}$ phase of the cell cycle (Assoian, 1997; Schwartz, 1997). Additionally, other cellular processes, such as differentiation, control of programmed cell death and cell motility, are mediated through the cooperation between adhesion and growth factor-signaling pathways (Howe et al., 1998). The anchorage requirement for proliferation is abrogated in many types of tumor cells, resulting in the ability to undergo cell division irrespective of the surrounding extracellular matrix (ECM) environment (Schwartz, 1997; Inoue et al., 1996). Hence, the biological importance of tight control of adhesion-mediated signals has particular relevance to cellular transformation and metastasis.

The integrins are the principal receptors responsible for binding to ECM component ligands, such as fibronectin (Hynes, 1992; Ruoslahti, 1991). Integrins are made up of dimeric combinations of one alpha and one beta subunit; the exact pairing determines the affinity for different ECM components. Engagement and clustering of integrin receptors has also been demonstrated to directly initiate a variety of signal transduction events. These include increases in the tyrosine phosphorylation state of a subset of proteins, activation of serine/threonine kinases, and alterations in cellular phospholipid and calcium levels (Aplin et al., 1998). These events are associated with the formation in cultured cells of focal adhesions: complex structures containing a variety of structural proteins (such as talin, vinculin and $\alpha$ actinin), signaling molecules (e.g. focal adhesion kinase $(\mathrm{FAK})$ ), and adaptor molecules (including paxillin, tensin and $\left.\mathrm{p} 130^{\mathrm{cas}}\right)$. Focal adhesions function to link the integrin cytoplasmic tails to the actin cytoskeleton and have been shown to be important in cell spreading and motility (Burridge et al., 1992; Cary et al., 1996; Richardson and Parsons, 1996; Romer et al., 1994).

The function of integrin-mediated assemblies is also dependent upon the activity of the Rho family of GTPases. Cdc42 and Rac1 are both involved in the formation of small focal complexes and also control the polymerization of actin into filopodial and lamellipodial structures, respectively (Kozma et al., 1995; Ridley et al., 1992; Nobes and Hall, 1995). RhoA activity rapidly induces the formation of stress 
fibers and focal adhesions by generating cellular tension (Ridley and Hall, 1992; Chrzanowska-Wodnicka and Burridge, 1996). The focal complexes formed by Cdc42 and Rac were identified as vinculin and phosphotyrosine-positive structures present at the tips of filopodia, or at the leading edge of lamellipodia, and are morphologically distinct from Rhoregulated focal adhesions (Nobes and Hall, 1995; Ridley et al., 1992). Cdc42 and Rac have also been demonstrated to activate the c-Jun kinase $(\mathrm{JNK}) /$ stress-activated protein kinase cascade, while they do not directly activate the MAPK/extracellular signal-regulated kinases (ERK) pathway (Coso et al., 1995; Minden et al., 1995; Olson et al., 1995). Interestingly activation of Rho, by the guanine exchange factors, dbl and lbc, also induces anchorage-independent, but serum-dependent cell growth (Schwartz et al., 1996). However, it is uncertain at present whether integrin engagement directly leads to the activation of these GTPases or if they act in parallel.

In addition to pathways directly activated upon cell adhesion, integrins exert their actions by subtly modulating pathways mediated by soluble growth factors and differentiation factors (Schwartz, 1997; Howe et al., 1998). Key regulators of many of these processes are $\mathrm{p} 42^{\mathrm{MAPK}}$ and p44 ${ }^{\mathrm{MAPK}}$, also referred to as ERK1 and ERK2 (Cobb et al., 1994). We and others have previously shown that anchorage of NIH3T3 fibroblasts to fibronectin permits efficient growth factor signaling to $\mathrm{p} 42^{\mathrm{MAPK}}$ and $\mathrm{p} 44^{\mathrm{MAPK}}$ as compared to cells maintained in suspension (Miyamoto et al., 1996; Lin et al., 1997b; Renshaw et al., 1997). Integrin receptors are strongly implicated in this effect as antibody-mediated engagement and clustering of $\alpha 5 \beta 1$ integrins, the principal cellular receptor for fibronectin, on cells in suspension mimics anchorage-enhanced signaling (Miyamoto et al., 1996).

Activation of MAPK results in phosphorylation of cytoplasmic targets, such as pp $90^{\mathrm{RSK}}$ and phospholipase $\mathrm{A}_{2}$, and in the redistribution of MAPK from the cytoplasm to the nucleus where it is capable of regulating several transcription factors, ultimately leading to changes in gene expression (Davis, 1995; Treisman, 1996). As previously noted, both cell anchorage and growth factors are necessary for passage through the $G_{1}$ phase of the cell cycle (Bohmer et al., 1996). Traversing this section of the cell cycle requires cyclin Dcyclin-dependent kinase (cdk) 4/6 and cyclin E-cdk2 complex activity. Cyclin D1 expression is reduced in quiescent 3T3 cells in suspension (Zhu et al., 1996) and forced cyclin D1 expression in suspended cells enables cell cycle progression of rat fibroblasts (Resnitzky, 1997). In addition, cells maintained in suspension have reduced cyclin E-cdk2 activity, probably due to alterations in levels of the cdk inhibitors, p21 and p27 (Zhu et al., 1996; Fang et al., 1996). As the MAPK/ERK pathway has been shown to impact on the levels of cyclin D1 (Lavoie et al., 1996), adhesion control of this cascade may be an important prerequisite for the anchoragedependent regulation of events leading to cell cycle progression.

Studies to date on adhesion control of signaling to MAPK have focused on pinpointing the step(s) in the MAPK cascade where the growth factor and integrin signaling pathways converge to give this synergistic effect. Growth factor binding to its cognate receptor tyrosine kinase initiates a sequence of events leading to activation of the GTP-binding protein Ras
(Marshall, 1995). Ras recruits the serine/threonine kinase Raf to the plasma membrane, where it phosphorylates and activates the MAPK/ERK kinase, MEK, which in turn phosphorylates and activates $\mathrm{p} 42^{\mathrm{MAPK}}$ and $\mathrm{p} 44^{\mathrm{MAPK}}$ (Brunet and Pouyssegur, 1998). However, differing experimental systems have provided alternative mechanisms for integrinmitogen collaboration, whereby cells on which the integrins are unoccupied can show deficiencies in signaling at the point of receptor tyrosine phosphorylation (Miyamoto et al., 1996), in Raf activation (Lin et al., 1997b), or in MEK activation (Renshaw et al., 1997).

In this study, we analyzed the role of focal adhesion and actin components associated with integrins in regulating epidermal growth factor signaling (EGF) to p42MAPK and p44MAPK. With the use of actin destabilizing drugs, we found that cells in which stress fibers were disrupted, but which were able to spread and retain a degree of cortical actin structure and small focal complexes, still responded to growth factor stimulation by efficiently activating $\mathrm{p} 42^{\mathrm{MAPK}}$ and $\mathrm{p} 44^{\mathrm{MAPK}}$. However, loss of this cortical actin network precluded effective signaling. We further demonstrate that structures formed by the activity of Rac and Rho GTPases, namely actin stress fibers, lamellipodia and mature focal adhesions, are not required for efficient signaling. In contrast, we were able to partially restore the efficiency of EGF signaling in suspension by the expression of a constitutively active form of $\mathrm{Cdc} 42$. These data indicate that a limited degree of adhesion-mediated cytoskeletal organization is essential for EGF signal transduction events to MAPKs and that, under certain conditions, $\mathrm{Cdc} 42$ regulated actin structures may be important in this process.

\section{MATERIALS AND METHODS}

\section{Materials}

cDNA for the constitutively active and dominant negative forms of Cdc42, Rac1 and RhoA in the pAX142 vector under the control of the elongation factor $1 \alpha$ promoter were gifts from Drs I. Whitehead and C. J. Der (Department of Pharmacology, University of North Carolina). pRc-CMV-C3 encoding the $\mathrm{C} 3$ exotoxin was a gift from Dr J. Settleman (Massachusetts General Hospital, Boston) and pcDNA1-HA-p44 ${ }^{\text {MAPK }}$ containing the cDNA for a hemagglutinin tagged version of $\mathrm{p} 44^{\mathrm{MAPK}} / \mathrm{ERK} 1$ was originally from $\mathrm{Dr} \mathrm{J}$. Pouyssegur (Nice, France). The polyclonal anti-C-terminal FAK antibody, 5158, and anti-vinculin antibody were gifts from Dr Lew Romer (Departments of Pediatrics and Anesthesiology, University of North Carolina) and Dr Keith Burridge (Dept Cell Biology and Anatomy, University of North Carolina), respectively. The following materials were purchased from the given suppliers: human fibronectin (Collaborative Biomedical Products, Bedford, MA); cytochalasin D, TRITC-labeled phalloidin and fluorophoreconjugated secondary antibodies (Sigma, St Louis, MO); latrunculin A (Molecular Probes, Eugene, OR); green fluorescent protein (GFP) vector, pGreen Lantern-1 (Gibco BRL, Gaitherburg, MD); FAK antibody (clone 2A7) and anti-phosphotyrosine antibody, 4G10 (Upstate Biotechnologies Inc., Lake Placid, NY); anti-active MAPK (Promega, Madison, WI); other antibodies to MAPK, Sc-93 and Sc94, (Santa Cruz, CA); anti-paxillin monoclonal antibody clone 349 (Transduction Labs, Lexington, KY); anti-tubulin antibody clone KMX-1 (Boehringer Mannheim Corp., Indianapolis, IN); antihemagglutinin tag antibody, HA11, (Babco, Richmond, CA); and horseradish peroxidase (HRP)-linked secondary antibodies (Calbiochem, San Diego, CA). 


\section{Cell culture, cell adherence and preparation of cell lysate}

NIH3T3 cells were maintained in Dulbecco's minimal essential medium (DMEM) containing 10\% bovine calf serum, 50 units $/ \mathrm{ml}$ penicillin, and $50 \mu \mathrm{g} / \mathrm{ml}$ streptomycin. Confluent cells were serumstarved for 4 hours or overnight before detachment by $0.05 \%$ trypsin and $0.33 \mathrm{mM}$ EDTA; trypsin activity was subsequently neutralized with $1 \mathrm{mg} / \mathrm{ml}$ soybean trypsin inhibitor (Gibco BRL). Cells were suspended in DMEM with $2 \%$ BSA and incubated nonadherently at $37^{\circ} \mathrm{C}$ for 45 minutes in a rotator to allow kinases become quiescent. Cells were then plated onto dishes coated with $20 \mu \mathrm{g} / \mathrm{ml}$ fibronectin or $1 \mu \mathrm{g} / \mathrm{ml}$ poly-L-lysine and incubated at $37^{\circ} \mathrm{C}$ for the indicated times. Following incubations, cells were washed twice with cold PBS and then lysed in a modified RIPA buffer containing $50 \mathrm{mM}$ Hepes, pH 7.5, $1 \%$ NP-40, $0.5 \%$ sodium deoxycholate, $150 \mathrm{mM}$ $\mathrm{NaCl}, 50 \mathrm{mM} \mathrm{NaF}, 1 \mathrm{mM}$ sodium vanadate, $1 \mathrm{mM}$ nitrophenylphosphate, $5 \mathrm{mM}$ benzamidine, $0.2 \mu \mathrm{M}$ calyculin $\mathrm{A}, 2$ $\mathrm{mM}$ PMSF, and $10 \mu \mathrm{g} / \mathrm{ml}$ aprotinin. Total cell lysates were cleared by centrifugation at $16,000 \mathrm{~g}$ for 5 minutes at $4^{\circ} \mathrm{C}$. Protein concentration in the lysates was determined using the bicinchonic acid assay (Pierce, Rockford, IL).

\section{Plasmid transfections}

SuperFect (Qiagen Inc., Valencia, CA) was used for the transient transfection of NIH3T3 cells according to the manufacturer's instructions.

\section{Immunofluorescence microscopy}

Cells were fixed in $3.7 \%$ formaldehyde in Dulbecco's phosphate buffered saline (PBS) for 10 minutes, rinsed in PBS, and permeabilized for 5 minutes in PBS containing $0.5 \%$ Triton X-100. Non-specific staining was blocked with $2 \%$ BSA and coverslips were incubated with primary antibodies in $2 \%$ BSA/PBS. The coverslips were rinsed extensively in PBS and then stained with TRITC-conjugated goat anti-mouse IgG in $2 \%$ BSA/PBS for 60 minutes at ambient temperature. F-actin was labeled with TRITCconjugated phalloidin at a concentration of $100 \mathrm{ng} / \mathrm{ml}$ for 15 minutes. Following the antibody incubations, the coverslips were washed in PBS, rinsed in deionized water, and mounted in Permafluor (Thomas, Swedesboro, NJ). Coverslips were viewed on a Ziess Axiophot or an Olympus model BX-FLA microscope equipped for epifluorescence. Fluorescence micrographs were taken on T-max 400 film (Kodak Co., Rochester, NY) or images were captured using Scion image software.

\section{Immunoprecipitation, western blot, and immune complex kinase assays}

Cell lysates were first incubated with antibody recognizing either FAK, p42 and p44 forms of MAPK, or HA-tagged MAPK for 2 hours at $4{ }^{\circ} \mathrm{C}$, followed by the addition of Protein G-Sepharose, and then further incubated for 2 hours at $4^{\circ} \mathrm{C}$. Western analysis was carried out as previously described (Lin et al., 1997a). Immunoreactivity was detected on Hyperfilm using enhanced chemiluminescence (Amersham Corp., Arlington Heights, IL). Bands from western blots were quantitated using a GS-670 model densitometer (Bio-Rad Laboratories, Richmond, CA).

For immune complex kinase assays, the precipitates were washed 3 times with cold washing buffer $(0.25 \mathrm{M}$ Tris-HCl, $\mathrm{pH} 7.5,0.1 \mathrm{M}$ $\mathrm{NaCl})$. The immunocomplexes were re-suspended in $40 \mu \mathrm{l}$ of kinase assay buffer containing $10 \mathrm{mM}$ Tris, pH 7.5, $10 \mathrm{mM} \mathrm{MgCl}_{2}, 1 \mathrm{mM}$ DTT, $10 \mu \mathrm{M}$ ATP, $5 \mu \mathrm{Ci}\left[{ }^{32} \gamma \mathrm{P}\right] \mathrm{ATP}(370 \mathrm{MBq} / \mathrm{ml}$; Du Pont, Boston, MA) and $10 \mu \mathrm{g}$ of myelin basic protein (MBP; Upstate Biotechnology Inc.), and incubated for 30 minutes at room temperature (Chen et al., 1996). Reactions were stopped by adding $13 \mu \mathrm{l}$ of $4 \times$ sample buffer and boiling for 3 minutes. The samples were subjected to SDS-PAGE, and the gels were dried. The dried gels were exposed to X-ray films, and the ${ }^{32} \mathrm{P}$-labeled substrate bands were quantified using a Storm 840 PhosphorImager with Image-QuaNT software (Molecular Dynamics, Sunnyvale, CA).

\section{Analysis of luciferase expression}

Cells were co-transfected with a plasmid encoding luciferase under the control of the c-fos promoter (gift from Dr D. Brenner, Department of Medicine, University of North Carolina) and the plasmid of interest. After a 4-hour transfection incubation period, cells were washed in PBS and DMEM containing $0.5 \%$ serum was added. Cells were incubated for a further 20 hours before lysis. Luciferase expression was determined using enhanced luciferase assay reagents on a Monolight 2010 model luminometer (Analytical Luminescence Laboratory, San Diego, CA). All transfections were performed in triplicate and luciferase activity was normalized to protein content and

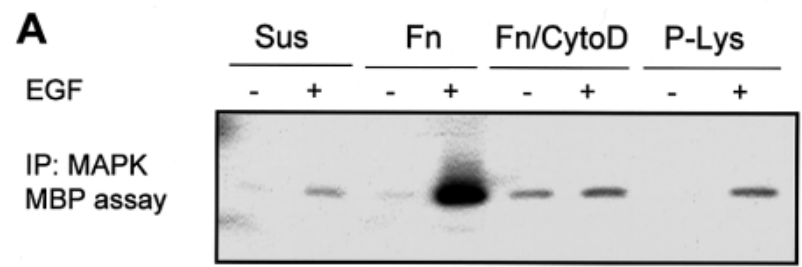

B
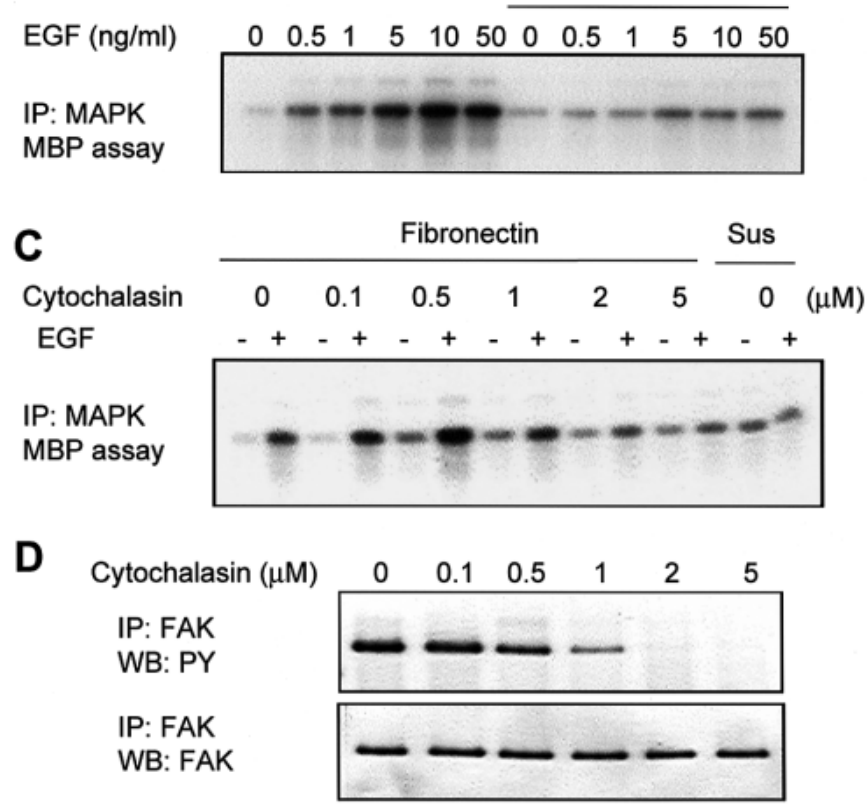

Fig. 1. Cytochalasin D treatment of cells reduces signaling to MAPK and FAK tyrosine phosphorylation. Serum-starved NIH3T3 cells were detached and incubated non-adherently for 45 minutes at $37^{\circ} \mathrm{C}$ in the presence of cytochalasin D or as a control, DMSO. Cells were allowed to adhere to fibronectin (Fn), poly-L-lysine (P-Lys), or maintained in suspension (Sus) for 2 hours before treatment with 20 $\mathrm{ng} / \mathrm{ml}$ EGF (+) for 5 minutes. Cells were lysed in modified RIPA buffer. MAPK activity was measured by an in vitro immunoprecipitation kinase assay using myelin basic protein (MBP) as substrate. (A) Activation of MAPK in cells adherent to different matrices or treated with $2 \mu \mathrm{M}$ cytochalasin D. (B) Cells treated with 2 $\mu \mathrm{M}$ cytochalasin $\mathrm{D}$ or with solvent control were stimulated with increasing concentrations of EGF. (C) Cells maintained in suspension or treated with increasing doses of cytochalasin D were stimulated (+) with $20 \mathrm{ng} / \mathrm{ml}$ EGF for 5 minutes. (D) Cells were allowed to adhere to fibronectin-coated plates in the presence of increasing concentrations of cytochalasin D. FAK was immunoprecipitated (IP) and analyzed by western blotting (WB) for phosphotyrosine levels (PY) and for levels of FAK with an anti-FAK polyclonal antibody. In all cases, representatives from two-three separate experiments are shown. 
expressed as the fold-activation over vector control/fos-luciferase values. Background activity detected from non-transfected cell lysates represented less than $0.2 \%$ of the luciferase reading.

\section{RESULTS}

\section{Effect of cytochalasin D and latrunculin A on adhesion-dependent signaling}

Initially, to analyze the requirements for actin and focal adhesion structure in adhesion-dependent EGF signaling to MAPKs/ERKs, we utilized the actin cytoskeleton depolymerizing agents, cytochalasin D and latrunculin A. Cytochalasin D caps the growing end of actin fibers and inhibits direct integrin-mediated tyrosine phosphorylation of the focal adhesion proteins, FAK and paxillin (Burridge et al., 1992) and the integrin-mediated activation of p42 and p44 forms of MAPK (Chen et al., 1994). In agreement with previous studies (Lin et al., 1997b), EGF treatment of NIH3T3 cells maintained in suspension produced only a modest activation of $\mathrm{p} 42^{\mathrm{MAPK}}$ and $\mathrm{p} 44^{\mathrm{MAPK}}$ in comparison to cells attached to fibronectin (Fig. 1A). Cytochalasin Dtreatment $(2 \mu \mathrm{M}$ concentration) during adhesion also reduced ability of cells to activate MAPK upon an EGF stimulus (Fig. 1A). Cytochalasin D treatment did not alter the ability of cells to attach to fibronectin and was non-toxic, as upon replacing the medium with normal growth medium, cytochalasin Dtreated cells rapidly spread and were subsequently able to undergo cell division. Cells adherent 'non-specifically' to poly-lysine also activate MAPKs poorly in response to EGF indicating that permissive signaling is integrin-dependent (Lin et al., 1997b). The total levels of MAPK were equivalent under the individual conditions and similar results were obtained by western blotting with an anti-active MAPK antibody (data not shown). Inhibition of EGF signaling to MAPK caused by $2 \mu \mathrm{M}$ cytochalasin treatment was evident over the $0.5 \mathrm{ng} / \mathrm{ml}-50 \mathrm{ng} / \mathrm{ml}$ range of EGF concentrations that we tested (Fig. 1B).

Since other studies have shown that cytochalasin-disruption of the actin cytoskeleton and focal adhesion formation failed to inhibit activation of MAPKs in Swiss 3T3 fibroblasts and in primary astrocyte cultures (Seufferlein et al., 1996; Cazaubon et al., 1997), we next analyzed the dose dependency of the cytochalasin D responses with regard to alterations in FAK tyrosine phosphorylation and cell morphology, in addition to EGF-mediated activation of MAPK. In control cultures and cultures treated with low concentrations of cytochalasin D (0.1$1 \mu \mathrm{M})$, cells were able to efficiently signal to MAPKs in response to an EGF stimulus (Fig. 1C). In contrast, when cultures were treated with higher doses of cytochalasin D or maintained in suspension, EGF-treatment poorly stimulated the activation of MAPKs (Fig. 1C). Integrin-mediated tyrosine phosphorylation of FAK was largely unaffected by low concentrations of cytochalasin $\mathrm{D}$, but was inhibited at $1-2 \mu \mathrm{M}$ concentrations and was undetected at $5 \mu \mathrm{M}$ (Fig. 1D). In agreement with our previous findings, FAK tyrosine
Fig. 2. Actin and focal adhesion structures in cytochalasin Dtreated cells. Serum-starved NIH3T3 cells were detached and incubated nonadherently for 45 minutes at $37^{\circ} \mathrm{C}$ in the presence of solvent control or increasing concentrations of cytochalasin D: (A and G) DMSO (B) $0.1 \mu \mathrm{M}$ (C) $0.5 \mu \mathrm{M}$, (D and H) $1.0 \mu \mathrm{M}$; (E and I) $2.0 \mu \mathrm{M}$; (F) $5.0 \mu \mathrm{M}$. Cells were allowed to adhere to fibronectin-coated coverslips for 2 hours and were then fixed. Immunofluorescence labeling was carried out with TRITC-

conjugated phalloidin to label $\mathrm{F}$ actin (A-F) or with anti-

phosphotyrosine antibody (G-I). Bars, $40 \mu \mathrm{M}$.
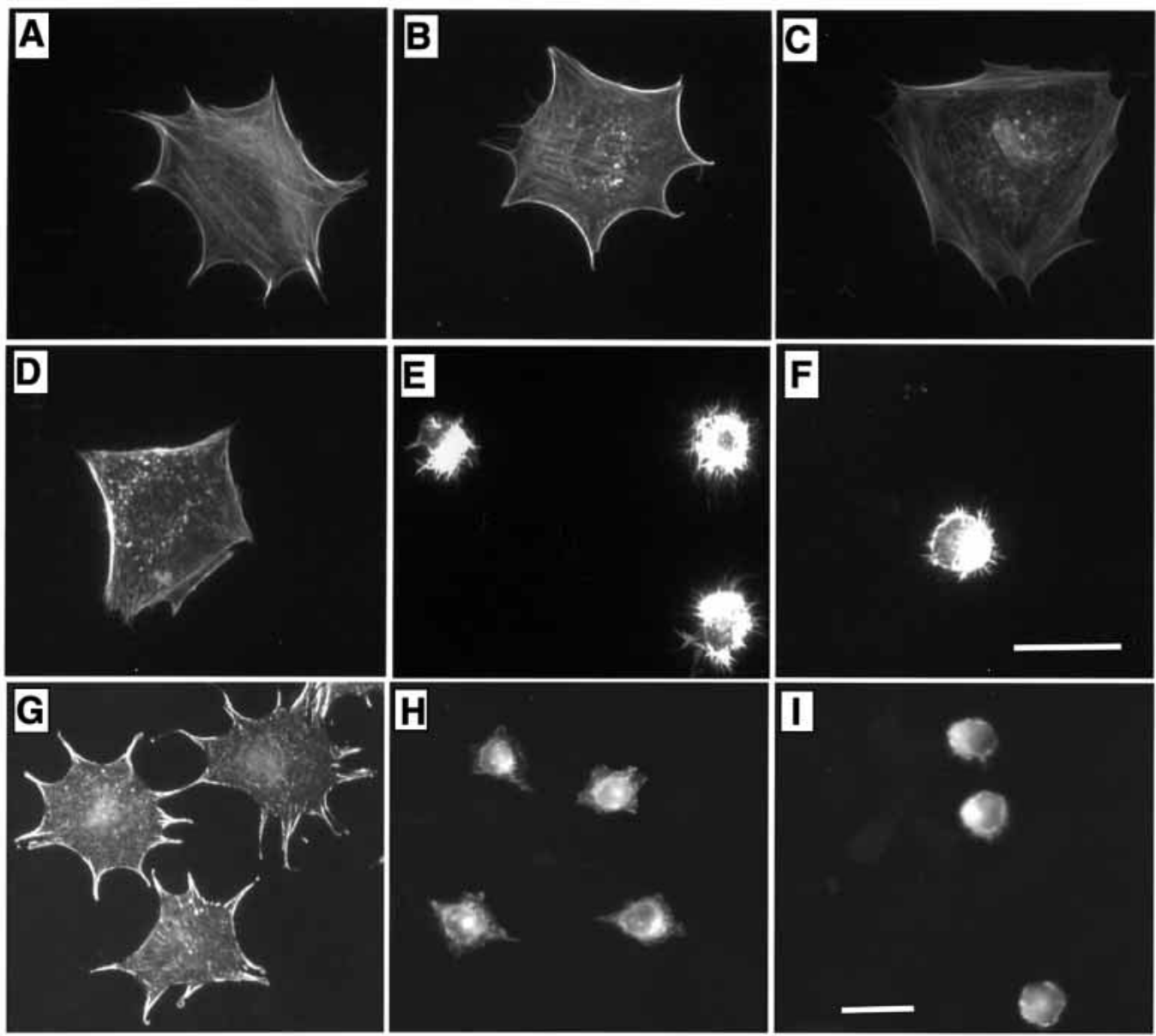
Fig. 3. Latrunculin A-inhibition of the formation of actin and focal adhesion structures. Serumstarved NIH3T3 cells were detached and incubated nonadherently for 45 minutes at $37^{\circ} \mathrm{C}$ in the presence of solvent control (A, C and $\mathrm{E}$ ) or $1 \mu \mathrm{g} / \mathrm{ml}$ latrunculin A (B,D,F). Cells were allowed to adhere to fibronectin-coated coverslips for 2 hours and were then fixed. Immunofluorescence labeling was carried out with (A and B) TRITC-conjugated phalloidin to label F-actin; (C and D) a monoclonal antitubulin antibody and (E and $\mathrm{F})$ anti-vinculin antibody. Bar, $40 \mu \mathrm{M}$.
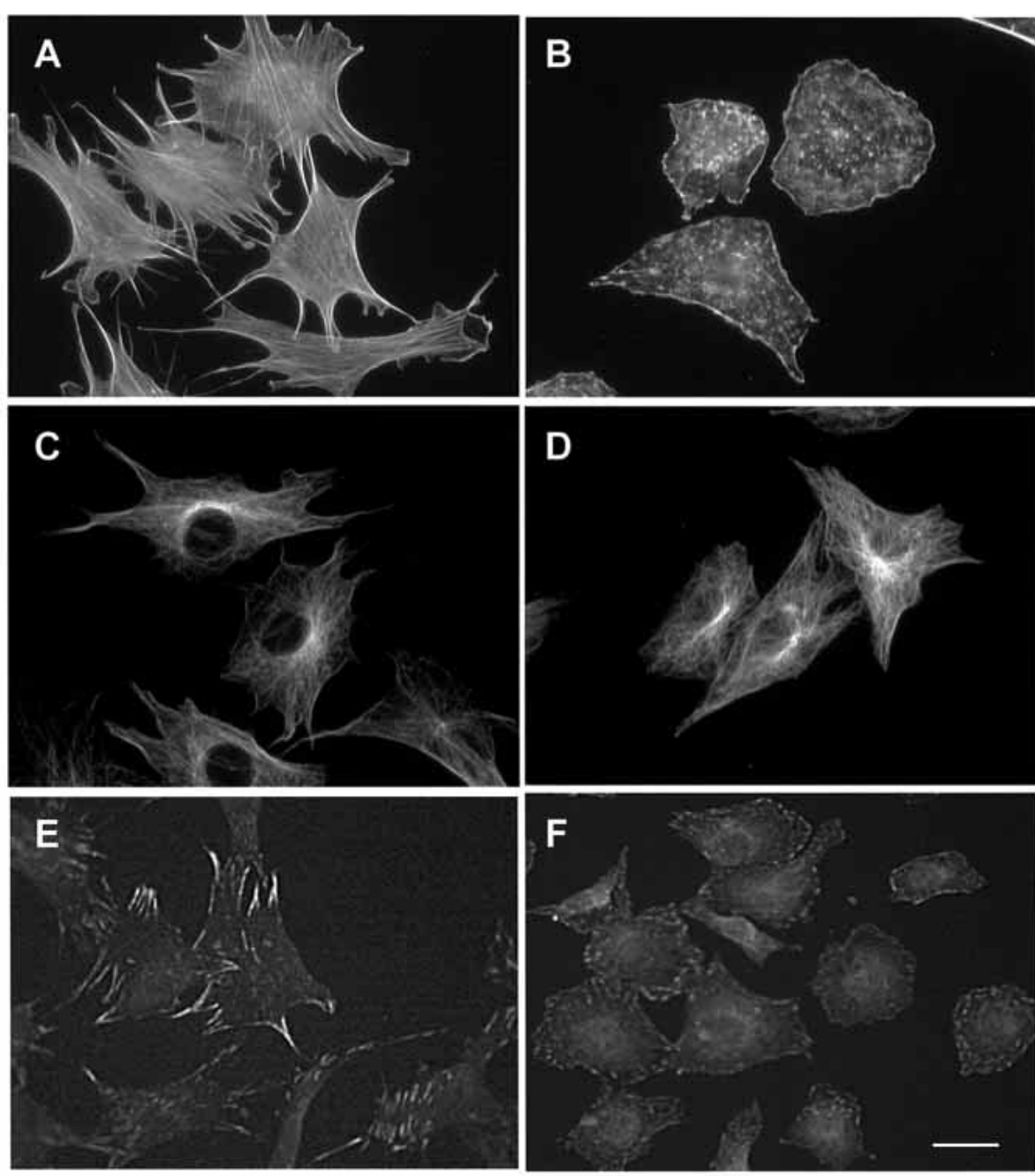

phosphorylation was unaffected upon EGF treatment (Lin et al., 1997a). Upon morphological analysis it was observed that low cytochalasin D concentrations primarily destabilized actin stress fibers traversing the cell body, whereas when concentrations at or above $2 \mu \mathrm{M}$ were used the cortical actin network that maintains the spread morphology of the cells was disrupted (Fig. 2). Immunofluorescence studies using antiphosphotyrosine antibody indicated that at concentrations of $1.0 \mu \mathrm{M}$ cytochalasin $\mathrm{D}$, mature focal adhesion structures were disassembled but that some positively staining punctate structures were retained, in comparison to control treated cells (Fig. 2G and H). These structures were absent in cells treated with $2.0 \mu \mathrm{M}$ cytochalasin D (Fig. 2I).

We next utilized a second class of actin cytoskeletal destabilizing agents, known as latrunculins, that also disrupt the actin cytoskeleton (Spector et al., 1983; Coue et al., 1987; Lamaze et al., 1996). Latrunculins act in a manner distinct from that of cytochalasins in that they sequester actin monomers, but like cytochalasins, they leave the microtubule network intact. NIH3T3 cells treated with $1 \mu \mathrm{g} / \mathrm{ml}$ latrunculin A during reattachment to fibronectin disrupted the ability of cells to form cortical actin filaments, actin stress fibers and focal adhesions (Fig. 3). Rather, latrunculin-A treated cells displayed diffuse actin staining with areas of punctate staining, although they retained an intact microtubular network and a degree of cell spreading (Fig. 3). In parallel, latrunculin A treatment reduced levels of active p42 ${ }^{\mathrm{MAPK}}$ and $\mathrm{p} 44^{\mathrm{MAPK}}$ in EGF treated samples, as determined by western blotting of lysates with an anti-active MAPK, and the level of FAK tyrosine phosphorylation in reattaching cells (Fig. 4A). In vitro phosphorylation assays showed that EGF activation of $\mathrm{p} 42^{\mathrm{MAPK}}$ and $\mathrm{p} 44^{\mathrm{MAPK}}$ was inhibited by approximately $40 \%$ in $1 \mu \mathrm{g} / \mathrm{ml}$ latrunculin Atreated cells (Fig. 4A and B). Thus, disruption of the actin cytoskeleton by a mechanism distinct from cytochalasin-D action also leads to a reduction in the ability of adherent cells to signal to MAPKs.

In summary, destabilization of actin stress fibers that traverse the cell body does not block EGF signaling to MAPK. However, use of higher doses of cytochalasin or the use of latrunculin A to destabilize both traversing stress fibers and cortical actin networks, blocks the activation of MAPK by EGF. This loss of signaling correlated with the loss of FAK tyrosine phosphorylation despite the maintenance of cell adhesion and was not simply due to alterations in cell shape.

\section{RhoA-mediated changes in actin stress fibers and focal adhesions do not impinge upon adhesion- dependent activation of MAPK}

The small GTP-binding protein RhoA mediates the formation 
Fig. 4. Latrunculin-A treatment inhibits EGF signaling to $\mathrm{p} 42$ and p44-MAPKs. Serum-starved NIH3T3 cells were detached and incubated nonadherently. Cells were serum-starved, maintained in suspension (Sus) or allowed to reattach to fibronectin coated dishes (Fn) in the presence of $1 \mu \mathrm{g} / \mathrm{ml}$ latrunculin A or solvent control. After two hours, cells were stimulated (+) with $5 \mathrm{ng} / \mathrm{ml}$ EGF. (A) Active and total MAPK levels were determined by western blotting of cellular lysates. FAK tyrosine phosphorylation was determined by immunoprecipitated (IP) followed by western blotting (WB) for phosphotyrosine levels (PY) and for levels of FAK with an anti-FAK polyclonal antibody. (B) MAPK activity was quantified by an in vitro immunoprecipitation kinase assay and by PhosphorImaging. The mean and s.d. from three independent experiments are represented.
A

EGF
Latrunculin A

\begin{tabular}{cccccc}
\multicolumn{2}{c}{ Sus } & & \multicolumn{3}{c}{ Fn } \\
\cline { 1 - 2 } \cline { 5 - 6 } & + & - & + & - & + \\
- & - & - & - & + & +
\end{tabular}

WB: active MAPK $\ldots \ldots=\longleftarrow$ p44

WB: MAPK

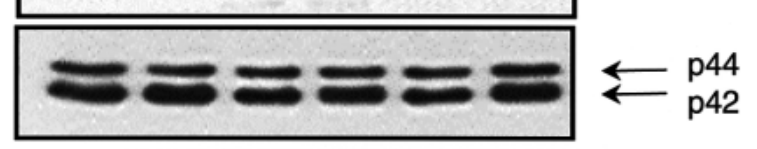

IP: FAK

WB: PY

IP: FAK

WB: FAK

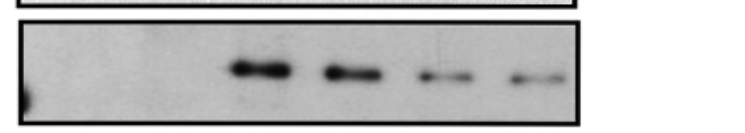

B

MBP phosphorylation assay
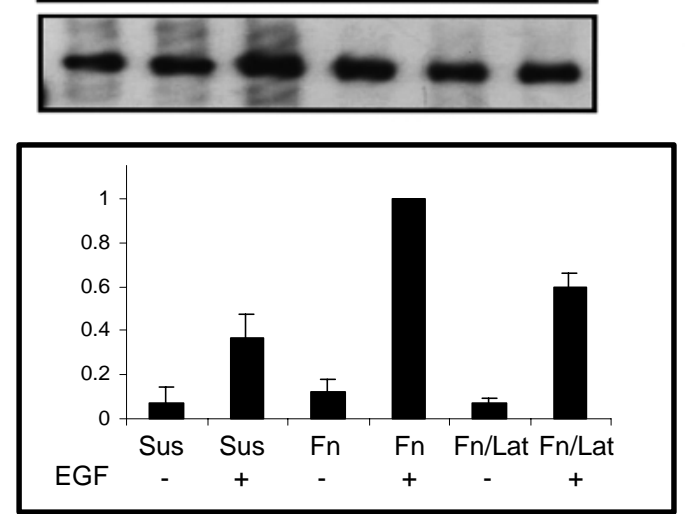

of actin stress fibers and focal adhesions induced by adhesion or growth factors in fibroblasts (Ridley and Hall, 1992; Barry and Critchley, 1994; Hotchin and Hall, 1995). In addition, other members of the Rho family, namely Cdc 42 and Rac1, have been shown to mediate the formation of peripheral actin structures and focal complexes (Nobes and Hall, 1995; Ridley et al., 1992). Thus, we analyzed the role of these Rho family GTPases in mediating adhesion-dependent EGF signaling to MAPK. To do this we utilized cDNA constructs encoding a specific inhibitor of a Rho GTPase (C3 exoenzyme), constitutively active versions of each GTPase (RhoA ${ }^{\mathrm{Q} 33 \mathrm{~L}}, \mathrm{Cdc} 42^{\mathrm{G} 12 \mathrm{~V}}$ and $\left.\mathrm{Rac}{ }^{\mathrm{Q} 61 \mathrm{~L}}\right)$ or a dominant negative version of $\mathrm{Cdc} 42\left(\mathrm{Cdc} 42^{\mathrm{T} 17 \mathrm{~N}}\right)$. The C3 Clostridium botulinum exoenzyme inactivates RhoA by ADP-ribosylating residue Asn ${ }^{41}$ (Aktories et al., 1992; Sekine et al., 1989). The constitutively active GTPases contain mutations that result in a reduction in the intrinsic and GAPstimulated GTPase activity, thereby stabilizing the GTP-bound form of each GTPase.

Initially, to confirm the effects of these constructs in NIH3T3 cells, we analyzed changes in the actin cytoskeleton and the ability to activate transcription from the serum response element containing the c-fos promoter linked to luciferase (Hill et al., 1995). Upon adhesion to fibronectin, vector control transfected cells displayed normal fibroblast morphology with pronounced actin stress fibers and vinculin, paxillin and phosphotyrosine-staining focal adhesions (Fig. 5A and B, data not shown). In contrast, NIH3T3 cells expressing C 3 and plated on fibronectin exhibited a less extended cell shape with peripheral actin cables but few or no actin stress fibers (Fig. $5 \mathrm{C}$ and D). Furthermore, these C3-expressing cells lacked paxillin and vinculin-containing classical focal adhesions, although the presence of smaller punctate structures was observed (Fig. 5E,F,G,H).

RhoA ${ }^{\mathrm{Q} 63 \mathrm{~L}}$ expression in NIH3T3 cells led to an increase in actin stress fiber formation as measured by immunofluorescence staining for F-actin (Fig. 6A). Additionally, expression of RhoA ${ }^{\mathrm{Q} 63 \mathrm{~L}}$ in low serum conditions gave a 2.5 -fold increase in c-fos promoter-driven luciferase activity (Fig. 6B). Staining for F-actin demonstrated that cells expressing constitutively active Rac induced the formation of numerous actin-containing lamellipodiae (Fig. 6A). Expression of $\mathrm{Cdc} 42^{\mathrm{G} 12 \mathrm{~V}}$ led to the formation numerous actin-containing membrane protrusions and membrane ruffles after 30 minutes of attachment and spreading on fibronectin (Fig. 6A). Expression of Cdc42 ${ }^{\mathrm{T} 17 \mathrm{~N}}$ in NIH3T3 cells under these conditions lead to an inability to spread properly after 30 minutes of adhesion to fibronectin, giving rise to a stellate cell morphology exhibiting numerous slender actincontaining protrusions (Fig. 6A). $\mathrm{Cdc}^{2} 2^{\mathrm{G} 12 \mathrm{~V}}$ and $\mathrm{Rac}{ }^{\mathrm{Q}} 1 \mathrm{~L}$ expression showed 3.5- and 3.9-fold enhancement of luciferase expression, respectively (Fig. 6B).

Next we analyzed the effect of Rho GTPase-mediated actin and focal adhesion structures in adherent cells on EGF signaling to MAPK. Cells were co-transfected with GTPases or GTPase inhibitors and an epitope-tagged MAPK construct (HAp44MAPK). EGF-stimulation of MAPK activity was analyzed from cells allowed to re-adhere to fibronectin, by immunoprecipitation with a HA-specific antibody followed by in vitro kinase assays. To initially study the role of RhoA-mediated structures, cells were co-transfected with HA-p44MAPK and C3. In agreement with the findings with endogenous MAPK, HAp44MAPK activity was enhanced upon EGF treatment when cells were adherent to fibronectin compared to cells maintained in 
suspension (Fig. 7A). EGF-mediated signaling to HA-p44MAPK in C3-expressing adherent cells was comparable to the activation in vector transfected cells (Fig. 7A), indicating that the signaling pathway to MAPK remains intact despite inhibition of RhoAmediated functions. As an extension of these findings, the effect of expression of a constitutively active form of RhoA (RhoA ${ }^{\mathrm{Q} 3 \mathrm{~L}}$ ) was examined in NIH3T3 cells. Expression of increasing amounts for RhoA $\mathrm{A}^{\mathrm{Q} 3 \mathrm{~L}}$ did not alter the ability of fibronectinadherent cells to activate HA-p44 ${ }^{\mathrm{MAPK}}$ in response to an EGF stimulus (Fig. 7B). These data suggest that RhoA activity and the presence of RhoA-mediated structures are not required for integrin-mitogen collaboration.

Additionally, we examined the role of structures mediated by other Rho family GTPases. Expression of constitutively active Rac did not enhance EGF activation of MAPK (Fig. 7C). Experiments utilizing a dominant-negative version of Rac, $\mathrm{Rac}^{\mathrm{T} 17 \mathrm{~N}}$, yielded poor expression of the co-transfected HAMAPK, probably due to cell toxicity induced by high levels of expression of $\operatorname{Rac}^{\mathrm{T} 17 \mathrm{~N}}$. To analyze if increased cellular Cdc42 activity could enhance EGF signaling in fibronectin adherent cells, cells were harvested after 30 minutes of adhesion, in order that events directly downstream of $\mathrm{Cdc} 42$ were being studied. Expression of $\mathrm{Cdc} 42^{\mathrm{G} 12 \mathrm{~V}}$ did not enhance EGF activation of MAPK in attached cells (Fig. 7D). Furthermore, expression of the dominant-negative form of $\mathrm{Cdc} 42$ $\left(\mathrm{Cdc} 42^{\mathrm{T} 17 \mathrm{~N}}\right)$ did not block EGF activation of MAPK (Fig. 7D).

\section{Cdc42 activity in suspension partially rescues EGF signaling to MAPK}

Due to their actions in regulating cytoskeletal structures, Rho GTPases were assessed for their ability to collaborate with EGF to activate the MAPK cascade in non-adherent cells. Constitutively active forms of $\mathrm{Cdc} 42$ (Cdc42G12V), Rac (Rac $\left.{ }^{\mathrm{Q} 1 \mathrm{~L}}\right)$ and Rho (RhoA $\left.{ }^{\mathrm{Q} 63 \mathrm{~L}}\right)$ were expressed in NIH3T3 cells. The activity of these constructs was confirmed by their stimulation of peripheral actin containing structures and
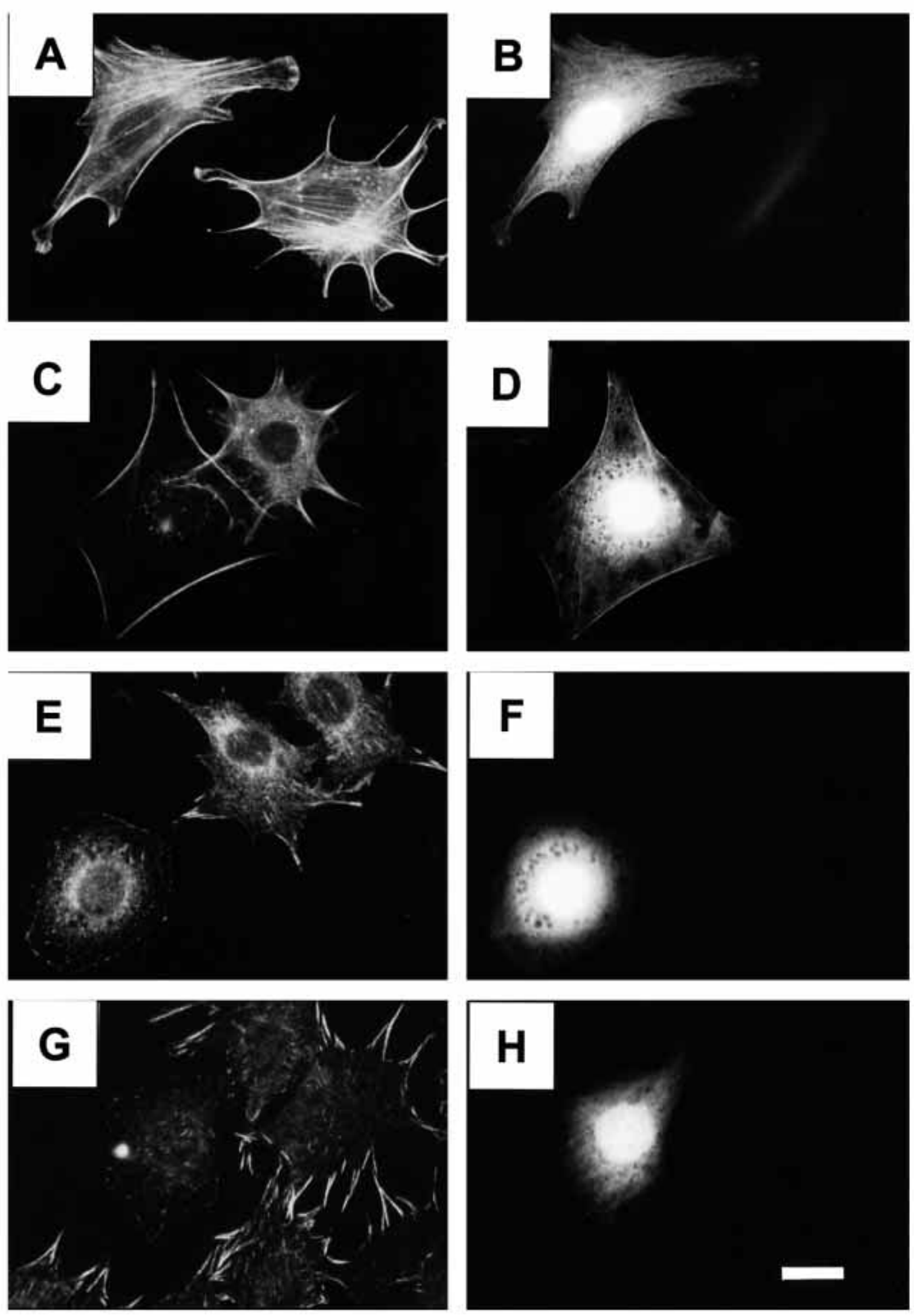

Fig. 5. C3-mediated inhibition of formation of actin stress fibers and focal adhesions. NIH3T3 cells were co-transfected with cDNA encoding GFP and either $\mathrm{C} 3$ exoenzyme $(\mathrm{C}-\mathrm{H})$ or empty vector $(\mathrm{A}$ and $\mathrm{B})$. Cells were serum-starved, incubated non-adherently and allowed to adhere as described in Fig. 1. Fixed cells were immunostained with either TRITC-labeled phalloidin (A and C), anti-paxillin (E) or antivinculin antibody $(\mathrm{G})$ and subsequently with a TRITC-labeled goat anti-mouse secondary antibody. $(\mathrm{B}, \mathrm{D}, \mathrm{F}, \mathrm{H})$ Identity of the transfected cells, indicated by their expression of GFP. Bar, $40 \mu \mathrm{M}$. 
Fig. 6. Constitutively-active forms of RhoA, $\mathrm{Rac}$ and $\mathrm{Cdc} 42$ stimulate the formation of actin-containing structures and c-fos luciferase activity. (A) NIH3T3 cells were cotransfected with GFP and either pAX142 encoding the constitutively active forms of RhoA (RhoA Q63L), Rac (Rac $\left.{ }^{Q 61 L}\right)$ and $\mathrm{Cdc} 42$ $\left(\mathrm{Cdc} 42^{\mathrm{G} 12 \mathrm{~V}}\right)$ or the dominant negative form of $\mathrm{Cdc} 42\left(\mathrm{Cdc} 42^{\mathrm{T} 17 \mathrm{~N})}\right.$. Cells were processed as described in Fig. 4, with the exception that Cdc42-transfected cell populations were fixed following 30 minutes of adhesion to fibronectin. Cells were immunostained for Factin. Transfected cells (arrowheads) were identified due to their expression of GFP. (B) Cells were co-transfected a construct containing the c-fos promoter coupled to the luciferase gene and vector (pAX142) or with pAX142 encoding RhoA ${ }^{\mathrm{Q} 3 \mathrm{~L}}, \mathrm{Cdc} 42^{\mathrm{G} 12 \mathrm{~V}}$ or Rac Q61L. Cells were maintained either in $0.5 \%$ serum and lysed 24 hours after the start of the transfection. Luciferase activity determined as in Materials and Methods. Shown is the mean and standard deviation of at least 6 individual transfections.

A
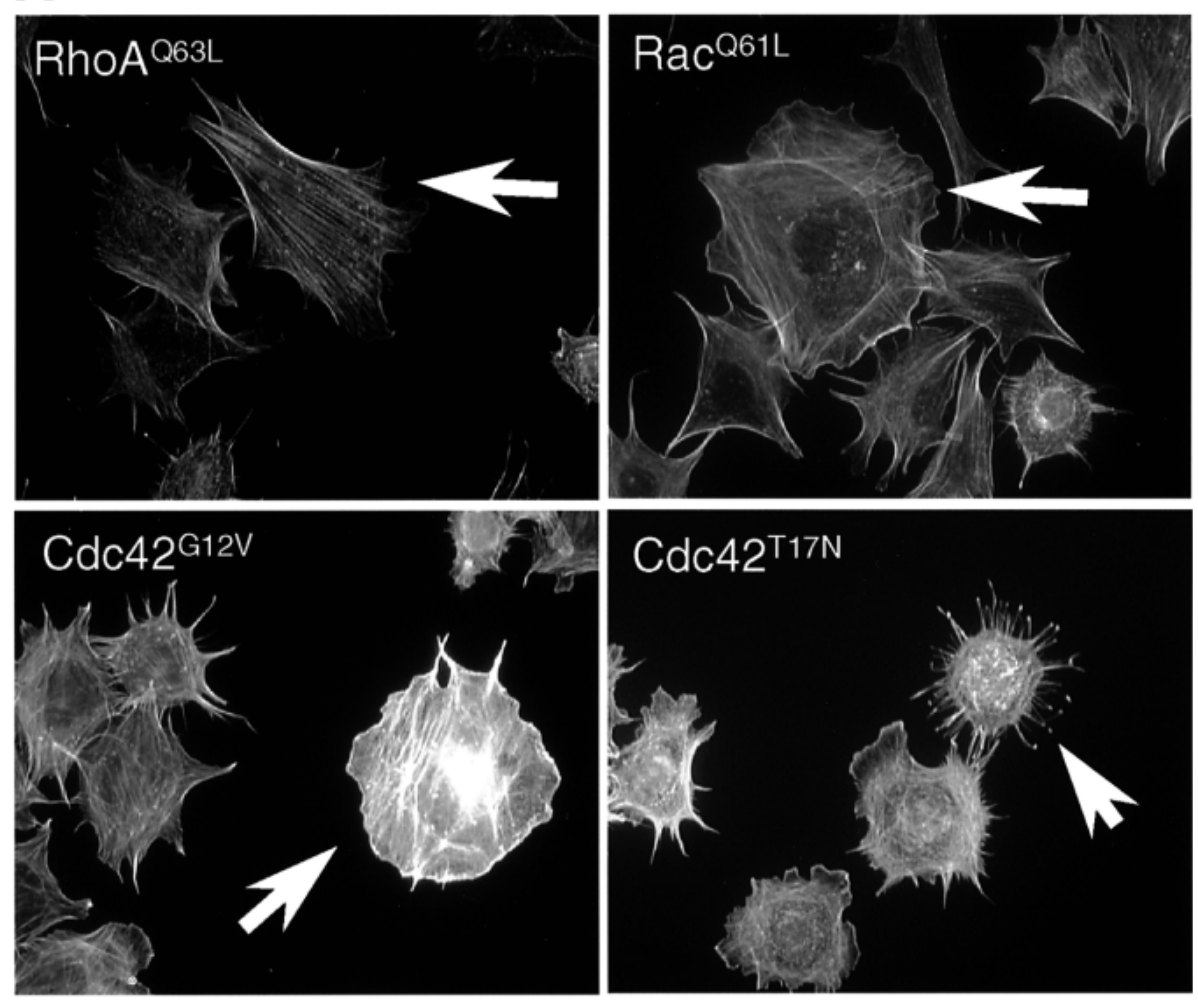

B

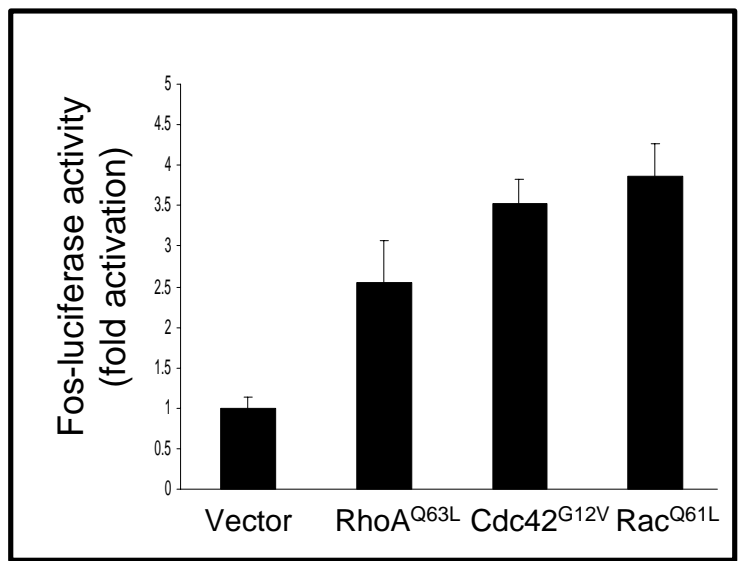

In summary, these data indicate that $\mathrm{Cdc} 42$ activity can partially rescue EGF signaling in suspended cells, although in cells adhering to fibronectin, enhancement of Cdc42 activity does not lead to a comparative increase in EGF signaling to MAPKs.

\section{DISCUSSION}

A state of adherence is a requirement for most non-transformed cells to proliferate. Integrin receptors and possibly other cell adhesion molecules regulate the activation of signaling cascades leading to cell cycle progression. One can postulate that integrin receptors may perform this function by different means. Integrins have been shown to complex with a number of signaling molecules, including components in the 
A

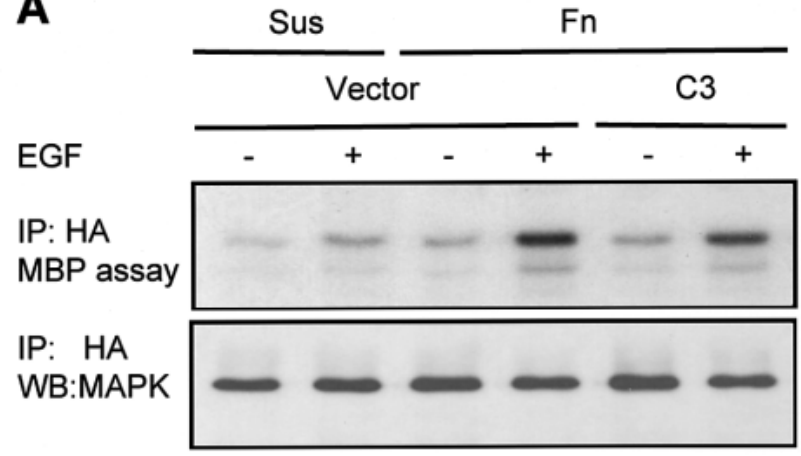

B

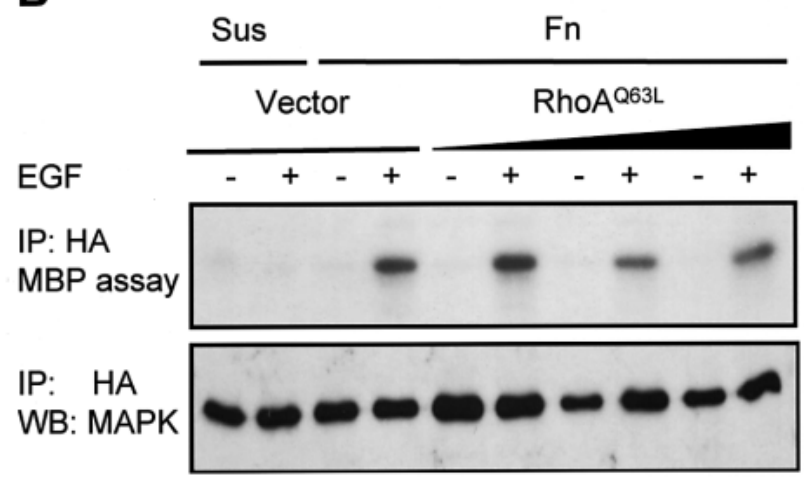

C

\begin{tabular}{|c|c|}
\hline Sus & \\
\hline Vector & $\operatorname{Rac}^{0611}$ \\
\hline
\end{tabular}

EGF

\begin{tabular}{lllllll}
- & + & - & + & - & + \\
& & & & \\
\hline & & & &
\end{tabular}

IP: HA

WB:MAPK

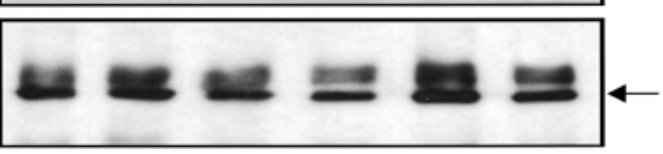

D

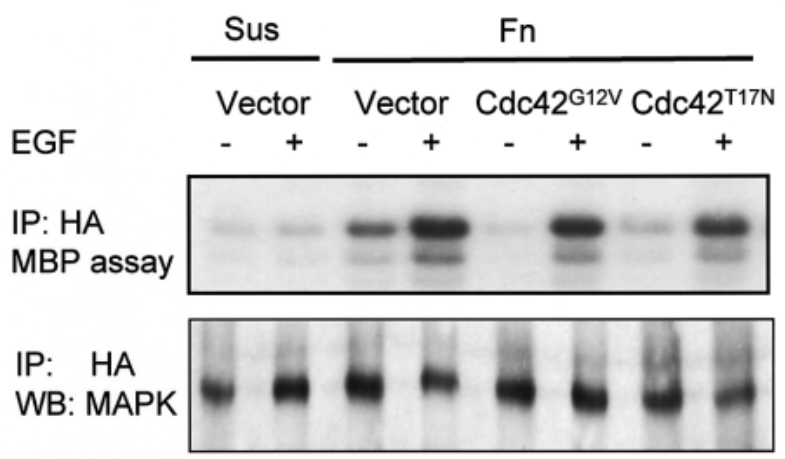

Fig. 7. Rho GTPase-mediated changes in the actin cytoskeleton do not affect EGF signaling to p44-MAPK in adherent cells. NIH3T3 cells were co-transfected with cDNA encoding a hemagglutinin-tagged ERK1 and (A) the C3 exoenzyme, as indicated, (B) increasing amounts of a constitutively active form of RhoA, (C) a constitutively active form of Rac and (D) constitutively active and dominant negative forms of Cdc42 $\left(\mathrm{Cdc} 42^{\mathrm{G} 12 \mathrm{~V}}\right.$ and $\left.\mathrm{Cdc} 42^{\mathrm{T} 17 \mathrm{~N}}\right)$. Transfection DNA levels were made up to $2 \mu \mathrm{g}$ with the appropriate empty vector (pRc-CMV or pAX142).

Transfected cells were serum-starved, maintained in suspension before replating on fibronectin. Cells were stimulated (+) with $5 \mathrm{ng} / \mathrm{ml}$ EGF for 5 minutes and HA-p44MAPK was immunoprecipitated from detergent-soluble lysates with an anti-HA antibody (HA11). p44 ${ }^{\mathrm{MAPK}}$ activity was determined by measuring the incorporation of ${ }^{32} \mathrm{P}$ into MBP. The levels of expressed HA-p44MAPK were assessed by western blotting of HAimmunoprecipitates with anti-MAPK antibody. Shown are representatives of two (C) or three (A, B, D) independent experiments. (C) Arrow indicates the HA-MAPK band. (D) Cells transfected with HA-p $44^{\mathrm{MAPK}}$ and Cdc $42^{\mathrm{G} 12 \mathrm{~V}}$ or Cdc $42^{\mathrm{T} 17 \mathrm{~N}}$ were processed as before, except that they were allowed to adhere to Fn for 30 minutes before EGF stimulation.

MAPK/ERK pathway (Miyamoto et al., 1995), and synergy may be achieved by the combined activation of the cascade from two different sources. Such a model has been proposed for direct integrin signaling to MAPK by which calveolin links the extracellular and/or transmembrane domains of the $\alpha$ chain of the integrin receptor to the adaptor protein, Shc, which in turn triggers signaling to MAPK (Wary et al., 1996). Secondly, since structural proteins are also recruited to sites of integrin engagement (Miyamoto et al., 1995), integrins may assemble a platform enabling efficient signaling processes to occur. Thus, we probed the importance of focal adhesions and the actin cytoskeleton in the facilitation of growth factor signaling.

We have utilized two approaches, namely drug based disruption of the actin cytoskeleton, and secondly, overexpression of proteins that mediate the formation or disassembly of actin-containing and focal adhesion structures. Both cytochalasin D and latrunculin A, agents that disrupt the actin cytoskeleton by differing mechanisms, decreased the efficiency of EGF signaling to MAPK in fibronectin adherent cells. These findings correlate with the use of cytochalasin D to block mitogen-stimulated entry of fibroblasts into S-phase
(Bohmer et al., 1996). At concentrations used to obtain these effects, both stress fiber and cortical actin networks were disrupted although a quite distinct cellular morphology was observed with the use of each drug. These findings, in addition to studies with the $\mathrm{Cdc} 42^{\mathrm{T} 17 \mathrm{~N}}$ mutant that dramatically alters cells shape without affecting activation of MAPK, argue against the notion for changes in cell shape in determining the response of cells to growth factors. The reduction of EGF activation of MAPK also correlated with the loss of FAK tyrosine phosphorylation. It is uncertain whether FAK may play a direct role in permitting EGF signaling or whether the phosphorylation state of FAK serves as a marker for the presence of focal adhesions and focal complexes. In favor of the latter, we have previously shown that direct integrin-mediated activation of MAPK and tyrosine phosphorylation of FAK can be separated (Lin et al., 1997a). Our findings raise the possibility that components of the cortical actin network and/or the small focal complexes are required for signaling. From experiments utilizing either cytochalasin D or C3 toxin, it is evident that the presence of stress fibers and mature focal adhesions are not required for signaling. Thus, anchorage-dependent growth factor signaling to 


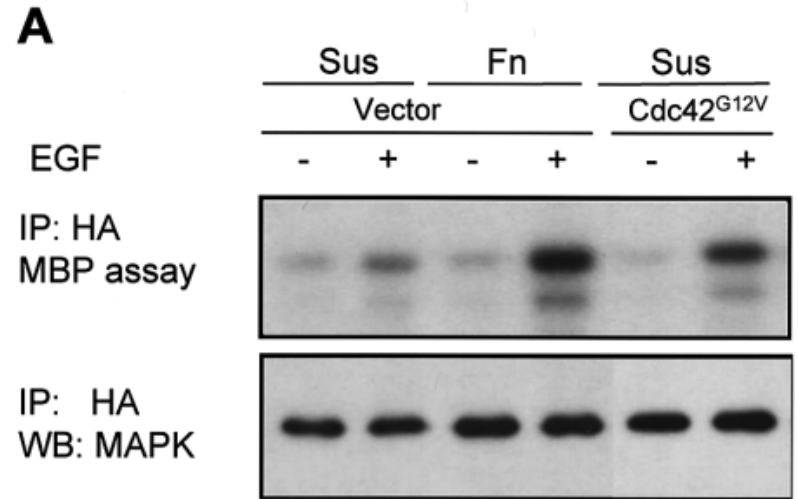

B
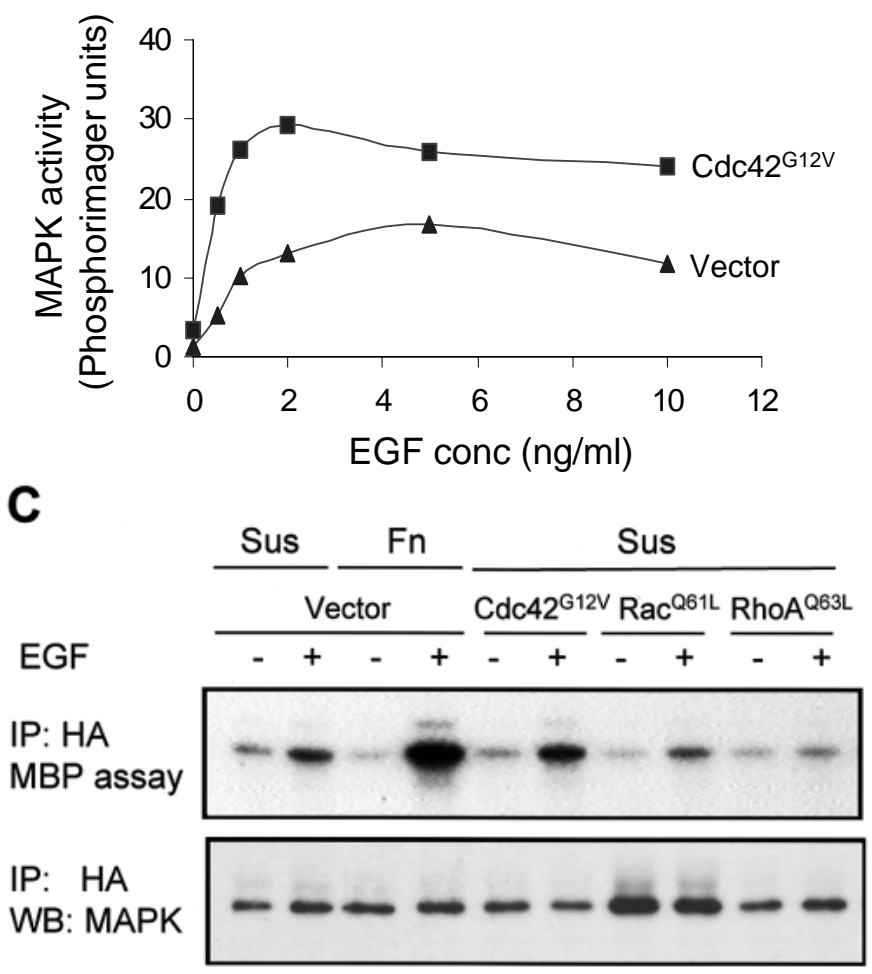

Fig. 8. Activated Cdc42 partially rescues EGF signaling in suspension. NIH3T3 cells were co-transfected with cDNA encoding a HA-p44MAPK and constitutively active forms of Rho GTPases. Serum-starved cells were rolled in suspension (Sus) or replated on fibronectin (Fn) for 3 hours before stimulation with EGF. MAPK activity was determined by immunoprecipitation and by in vitro kinase assay. Incorporation of ${ }^{32} \mathrm{P}$ into MBP was detected by autoradiography and western blots showing the level of expressed HA-p44MAPK are shown. (A) Cdc42 ${ }^{\mathrm{G} 12 \mathrm{~V}}$ and vector transfected cells, either in suspension (Sus) or adherent to fibronectin (Fn), were stimulated with EGF. Shown is a representative of three independent experiments. (B) $\mathrm{Cdc} 42^{\mathrm{G} 12 \mathrm{~V}}$ and vector transfected cells maintained in suspension were stimulated with a range of doses of EGF. Shown is a representative of two experiments with similar results. (C) Cells transfected with empty vector or constitutively active forms of Rho GTPases (Cdc42 ${ }^{\mathrm{T} 17 \mathrm{~N}}$, Rac ${ }^{\mathrm{Q} 61 \mathrm{~L}}$ and RhoA $\left.{ }^{\mathrm{Q} 63 \mathrm{~L}}\right)$ were stimulated with EGF either in suspension or after adhesion to fibronectin.

MAPK is independent of long-range actin structures and focal adhesions but appears to require the presence of localized membrane-associated actin or focal complex structures.
We have also explored the involvement of the Rho family GTPases, Cdc42 and Rac. These GTPases are upstream in the pathway leading to stimulation of JNK activity but do not directly activate ERK/MAPK (Coso et al., 1995; Minden et al., 1995; Olson et al., 1995), and play a pivotal role in the formation of peripheral actin cytoskeletal structures (Ridley et al., 1992; Nobes and Hall, 1995; Kozma et al., 1995). Our observations are in agreement with a linear relationship between $\mathrm{Cdc} 42$ and Rac, in that cells expressing active $\mathrm{Cdc} 42$ formed lamellipodial structures. In adherent cells, stimulation of the formation of lamellipodial structures and cell spreading or enhanced formation of actin stress fibers did not promote EGF activation of MAPK. This indicates that Rho and Rac do not increase the recruitment/activation of components necessary for integrin-mitogen collaboration beyond what is provided by cell adherence. We observe that Cdc42 enhanced EGF signaling to MAPK in non-adherent cells. No such effect was observed using an active form of Rac. This raises the possibility that $\mathrm{Cdc} 42$ may be normally activated upon adhesion to fibronectin and thus be placed on a pathway downstream of integrin engagement. Indeed expression of dominant negative forms of Cdc42 in NIH3T3 cells delayed cell spreading on fibronectin. There is little direct evidence to date indicating that integrins influence Rho family members, partly due to the lack of appropriate antibodies for measuring the GTP-bound levels of the GTPases. However, recent findings do indicate that $\mathrm{Cdc} 42$ and Rac activities leading to cell spreading and activation of downstream effectors are regulated by integrin engagement (Price et al., 1998). These and our findings suggest a linkage of integrins to GTPases that stimulate peripheral actin-containing structures. Furthermore, Cdc42 plays a role in integrin-dependent signaling events such as tyrosine phosphorylation of paxillin and the direct activation of the MAPK and protein kinase B pathways (Clark et al., 1998). This control may be mediated by integrin-regulation of guanine-nucleotide exchange factors, GTPase-activating proteins and guanine-nucleotide dissociation inhibitors for Cdc42 and/or Rac. Expression of either dominant-negative or constitutively active Cdc 42 failed to alter EGF activation of MAPK in cells plated on fibronectin. This may indicate that only a proportion of cellular $\mathrm{Cdc} 42$ is being regulated by integrins and that the activation of this pool is rapidly saturated upon adhesion to fibronectin. These findings again highlight the requirement for a limited degree of actin-containing structures for EGF signaling. It is likely that under our conditions the expression of the dominant-negative Cdc 42 was unable to destabilize these structures in fibronectin-adherent cells.

It is uncertain at this stage whether the Cdc42-mediated effect on MAPK activation in suspension may be due to polymerization of actin or due to effector protein binding and resultant activation of a signaling cascade. In hematopoietic cells, WASP, the Wiskett-Aldrich syndrome protein may link $\mathrm{Cdc} 42$ in a GTP-dependent manner to cytoskeletal rearrangements (Symons et al., 1996). However, WASP is expressed only in hematopoetic cells, and a more likely candidate in fibroblasts is the structurally similar N-WASP (Miki et al., 1998). Several effectors have been identified as binding to $\mathrm{Cdc} 42$ through recombinant proteins binding assays and two-hybrid screens (Ridley, 1996; Lim et al., 1996). Effector domain mutants have been useful to delineate 
downstream pathways and, for example, have been used to show that the JNK and cytoskeletal effects of Cdc42 and Rac are independently controlled (Lamarche et al., 1996). Thus effector domain mutants of $\mathrm{Cdc} 42$ may present a useful tool in further defining the effects of $\mathrm{Cdc} 42$ on growth factor signaling in suspension. The effects described here with $\mathrm{Cdc} 42$ remain a partial rescue. This may be caused by dual control of downstream effectors. Recently such a scenario has been described for the $\mathrm{Cdc} 42$ and Rac binding protein p65-PAK (p21 activated protein kinase) (Daniels et al., 1998). Studies in PC12 cells have demonstrated a role for p65-PAK in neurite outgrowth and that this function was dependent upon localization of $\mathrm{p} 65$-PAK to the membrane. Hence, full recovery of signaling in suspension may require molecules in addition to those regulated through $\mathrm{Cdc} 42$.

The findings described here further emphasize the influence of integrin engagement with ECM ligands on signaling leading to cell cycle progression. The mechanistic basis of this integrin-mediated regulation is now coming to light. It is apparent in our studies that mature focal adhesions are not essential for all integrin functions. Rather, it seems likely that less architecturally developed complexes impinge on downstream processes. This agrees with the in vivo situation where mature focal adhesion structures are not common place. Our studies do show a key role for integrin-actin linkages, the exact nature of which it will be important to further elucidate.

We are grateful to Drs Lew Romer, Jeffrey Settleman, Channing Der, Irene Zohn and Ian Whitehead for the generous gifts of antibody or plasmids. We thank Drs Danny Altschuler, Alan Howe and Mike Schaller for helpful discussion. This work was supported by a National Institute of Health grant (GM 26165) to R.L. Juliano.

\section{REFERENCES}

Aktories, K., Mohr, C. and Koch, G. (1992). Clostridium botulinum C3 ADP-ribosyltransferase. Curr. Topics Microbiol. Immunol. 175, 115-131.

Aplin, A. E., Howe, A., Alahari, S. K. and Juliano, R. L. (1998). Signal transduction and signal modulation by cell adhesion receptors: The role of integrins, cadherins, Ig-CAMs and selectins. Pharm. Rev. 50, 197-262.

Assoian, R. K. (1997). Anchorage-dependent cell cycle progression. J. Cell Biol. 136, 1-4.

Barry, S. T. and Critchley, D. R. (1994). The RhoA-dependent assembly of focal adhesions in Swiss 3T3 cells is associated with increased tyrosine phosphorylation and the recruitment of both pp125FAK and protein kinase C-delta to focal adhesions. J. Cell Sci. 107, 2033-2045.

Bohmer, R. M., Scharf, E. and Assoian, R. K. (1996). Cytoskeletal integrity is required throughout the mitogen stimulation phase of the cell cycle and mediates the anchorage-dependent expression of cyclin D1. Mol. Biol. Cell. 7, 101-111.

Brunet, A. and Pouyssegur, J. (1998). Mammalian MAP kinase modules: how to transduce specific signals. Essays Biochem. 32, 1-16.

Burridge, K., Turner, C. E. and Romer, L. H. (1992). Tyrosine phosphorylation of paxillin and pp125FAK accompanies cell adhesion to extracellular matrix: a role in cytoskeletal assembly. J. Cell Biol. 119, 893903.

Cary, L. A., Chang, J. F. and Guan, J. L. (1996). Stimulation of cell migration by overexpression of focal adhesion kinase and its association with Src and Fyn. J. Cell Sci. 109, 1787-1794.

Cazaubon, S., Chaverot, N., Romero, I. A., Girault, J. A., Adamson, P., Strosberg, A. D. and Couraud, P. O. (1997). Growth factor activity of endothelin-1 in primary astrocytes mediated by adhesion-dependent and independent pathways. J. Neurosci. 17, 6203-6212.

Chen, Q., Kinch, M. S., Lin, T. H., Burridge, K. and Juliano, R. L. (1994). Integrin-mediated cell adhesion activates mitogen-activated protein kinases. J. Biol. Chem. 269, 26602-26605.
Chen, Q., Lin, T. H., Der, C. J. and Juliano, R. L. (1996). Integrin-mediated activation of MEK and mitogen-activated protein kinase is independent of Ras. J. Biol. Chem. 271, 18122-18127.

Chrzanowska-Wodnicka, M. and Burridge, K. (1996). Rho-stimulated contractility drives the formation of stress fibers and focal adhesions. J. Cell Biol. 133, 1403-1415.

Clark, E. A., King, W. G., Brugge, J. S., Symons, M. and Hynes, R. O. (1998). Integrin-mediated signals regulated by members of the Rho family of GTPases. J Cell Biol. 142, 573-586.

Cobb, M. H., Xu, S., Hepler, J. E., Hutchison, M., Frost, J. and Robbins, D. J. (1994). Regulation of the MAP kinase cascade. Cell. Mol. Biol. Res. 40, 253-256.

Coso, O. A., Chiariello, M., Yu, J. C., Teramoto, H., Crespo, P., Xu, N., Miki, T. and Gutkind, J. S. (1995). The small GTP-binding proteins Rac1 and $\mathrm{Cdc} 42$ regulate the activity of the JNK/SAPK signaling pathway. Cell 81, 1137-1146.

Coue, M., Brenner, S. L., Spector, I. and Korn, E. D. (1987). Inhibition of actin polymerization by latrunculin A. FEBS Lett. 213, 316-318.

Daniels, D., Hall, P. S. and Bokoch, G. M. (1998). Membrane targeting of p21-activated kinase 1 (PAK1) induces neurite outgrowth from PC12 cells. EMBO J. 17, 754-764.

Davis, R. J. (1995). Transcriptional regulation by MAP kinases. Mol. Reprod. Dev. 42, 459-467.

Fang, F., Orend, G., Watanabe, N., Hunter, T. and Ruoslahti, E. (1996). Dependence of cyclin E-CDK2 kinase activity on cell anchorage. Science 271, 499-502.

Hill, C. S., Wynne, J. and Treisman, R. (1995). The Rho family GTPases RhoA, Rac1, and CDC42Hs regulate transcriptional activation by SRF. Cell 81, 1159-1170.

Hotchin, N. A. and Hall, A. (1995). The assembly of integrin adhesion complexes requires both extracellular matrix and intracellular Rho/Rac GTPases. J. Cell Biol. 131, 1857-1865.

Howe, A., Aplin, A. E., Alahari, S. K. and Juliano, R. L. (1998). Integrin signaling and cell growth control. Curr. Opin. Cell Biol. 10, 220-231.

Hynes, R. O. (1992). Integrins: versatility, modulation, and signaling in cell adhesion. Cell 69, 11-25.

Inoue, H., Yamashita, A. and Hakura, A. (1996). Adhesion-dependency of serum-induced $\mathrm{p} 42 / \mathrm{p} 44$ MAP kinase activation is released by retroviral oncogenes. Virology 225, 223-226.

Kozma, R., Ahmed, S., Best, A. and Lim, L. (1995). The Ras-related protein $\mathrm{Cdc} 42 \mathrm{Hs}$ and bradykinin promote formation of peripheral actin microspikes and filopodia in Swiss 3T3 fibroblasts. Mol. Cell. Biol. 15, 1942-1952.

Lamarche, N., Tapon, N., Stowers, L., Burbelo, P. D., Aspenstrom, P., Bridges, T., Chant, J. and Hall, A. (1996). Rac and Cdc42 induce actin polymerization and $\mathrm{G}_{1}$ cell cycle progression independently of p65PAK and the JNK/SAPK MAP kinase cascade. Cell 87, 519-529.

Lamaze, C., Chuang, T. H., Terlecky, L. J., Bokoch, G. M. and Schmid, S. L. (1996). Regulation of receptor-mediated endocytosis by Rho and Rac. Nature 382, 177-179.

Lavoie, J. N., G, L. A., Brunet, A., Muller, R. and Pouyssegur, J. (1996). Cyclin D1 expression is regulated positively by the p42/p44MAPK and negatively by the p38/HOGMAPK pathway. J. Biol. Chem. 271, 2060820616.

Lim, L., Manser, E., Leung, T. and Hall, C. (1996). Regulation of phosphorylation pathways by p21 GTPases. The p21 Ras-related Rho subfamily and its role in phosphorylation signalling pathways. Eur. $J$. Biochem. 242, 171-185.

Lin, T. H., Aplin, A. E., Shen, Y., Chen, Q., Schaller, M., Romer, L., Aukhil, I. and Juliano, R. L. (1997a). Integrin-mediated activation of MAP kinase is independent of FAK: evidence for dual integrin signaling pathways in fibroblasts. J. Cell Biol. 136, 1385-1395.

Lin, T. H., Chen, Q., Howe, A. and Juliano, R. L. (1997b). Cell anchorage permits efficient signal transduction between Ras and its downstream kinases. J. Biol. Chem. 272, 8849-8852.

Marshall, C. J. (1995). Opportunities for pharmacological intervention in the Ras pathway. Ann. Oncol. 6, 63-67.

Miki, H., Sasaki, T., Takai, Y. and Takenawa, T. (1998). Induction of filopodium formation by a WASP-related actin-depolymerizing protein $\mathrm{N}$ WASP. Nature 391, 93-96.

Minden, A., Lin, A., Claret, F. X., Abo, A. and Karin, M. (1995). Selective activation of the JNK signaling cascade and c-Jun transcriptional activity by the small GTPases Rac and Cdc42Hs. Cell 81, 1147-1157.

Miyamoto, S., Teramoto, H., Coso, O. A., Gutkind, J. S., Burbelo, P. D., Akiyama, S. K. and Yamada, K. M. (1995). Integrin function: molecular 
hierarchies of cytoskeletal and signaling molecules. J. Cell Biol. 131, 791805.

Miyamoto, S., Teramoto, H., Gutkind, J. S. and Yamada, K. M. (1996). Integrins can collaborate with growth factors for phosphorylation of receptor tyrosine kinases and MAP kinase activation: roles of integrin aggregation and occupancy of receptors. J. Cell Biol. 135, 1633-1642.

Nobes, C. D. and Hall, A. (1995). Rho, Rac, and Cdc42 GTPases regulate the assembly of multimolecular focal complexes associated with actin stress fibers, lamellipodia, and filopodia. Cell 81, 53-62.

Olson, M. F., Ashworth, A. and Hall, A. (1995). An essential role for Rho, Rac, and Cdc42 GTPases in cell cycle progression through $\mathrm{G}_{1}$. Science 269, 1270-1272.

Price, L. S., Leng, J., Schwartz, M. A. and Bokoch, G. M. (1998). Activation of Rac and Cdc42 by integrins mediates cell spreading Mol. Biol. Cell $\mathbf{9}$, 1863-1871.

Renshaw, M. W., Ren, X. D. and Schwartz, M. A. (1997). Growth factor activation of MAP kinase requires cell adhesion. EMBO J. 16, $5592-$ 5599.

Resnitzky, D. (1997). Ectopic expression of cyclin D1 but not cyclin E induces anchorage-independent cell cycle progression. Mol. Cell. Biol. 17, 56405647.

Richardson, A. and Parsons, T. (1996). A mechanism for regulation of the adhesion-associated protein tyrosine kinase pp125FAK. Nature 380, 538540.

Ridley, A. J. (1996). Rho: theme and variations. Curr. Biol. 6, 1256-1264.

Ridley, A. J. and Hall, A. (1992). The small GTP-binding protein Rho regulates the assembly of focal adhesions and actin stress fibers in response to growth factors. Cell 70, 389-399.

Ridley, A. J., Paterson, H. F., Johnston, C. L., Diekmann, D. and Hall, A. (1992). The small GTP-binding protein Rac regulates growth factor-induced membrane ruffling. Cell 70, 401-410.

Romer, L. H., McLean, N., Turner, C. E. and Burridge, K. (1994). Tyrosine kinase activity, cytoskeletal organization, and motility in human vascular endothelial cells. Mol. Biol. Cell. 5, 349-361.

Ruoslahti, E. (1991). Integrins. J. Clin. Invest. 87, 1-5.

Schwartz, M. A. (1997). Integrins, oncogenes, and anchorage independence. J. Cell Biol. 139, 575-578.

Schwartz, M. A., Toksoz, D. and Khosravi-Far, R. (1996). Transformation by Rho exchange factor oncogenes is mediated by activation of an integrindependent pathway. EMBO J. 15, 6525-6530.

Sekine, A., Fujiwara, M. and Narumiya, S. (1989). Asparagine residue in the Rho gene product is the modification site for botulinum ADPribosyltransferase. J. Biol. Chem. 264, 8602-8605.

Seufferlein, T., Withers, D. J., Mann, D. and Rozengurt, E. (1996) Dissociation of mitogen-activated protein kinase activation from $\mathrm{p} 125$ focal adhesion kinase tyrosine phosphorylation in Swiss 3T3 cells stimulated by bombesin, lysophosphatidic acid, and platelet-derived growth factor. Mol. Biol. Cell. 7, 1865-1875.

Spector, I., Shochet, N. R., Kashman, Y. and Groweiss, A. (1983). Latrunculins: novel marine toxins that disrupt microfilament organization in cultured cells. Science 219, 493-495.

Symons, M., Derry, J. M., Karlak, B., Jiang, S., Lemahieu, V., McCormick, F., Francke, U. and Abo, A. (1996). Wiskott-Aldrich syndrome protein, a novel effector for the GTPase $\mathrm{Cdc} 42 \mathrm{Hs}$, is implicated in actin polymerization. Cell $\mathbf{8 4}$, 723-734.

Treisman, R. (1996). Regulation of transcription by MAP kinase cascades. Curr. Opin. Cell Biol. 8, 205-215.

Wary, K. K., Mainiero, F., Isakoff, S. J., Marcantonio, E. E. and Giancotti, F. G. (1996). The adaptor protein She couples a class of integrins to the control of cell cycle progression. Cell 87, 733-743.

Zhu, X., Ohtsubo, M., Bohmer, R. M., Roberts, J. M. and Assoian, R. K. (1996). Adhesion-dependent cell cycle progression linked to the expression of cyclin D1, activation of cyclin E-cdk2, and phosphorylation of the retinoblastoma protein. J. Cell Biol. 133, 391-403. 